University of Nebraska - Lincoln

DigitalCommons@University of Nebraska - Lincoln

November 1999

Structural and magnetic properties of $\mathrm{FePt}: \mathrm{SiO}_{2}$ granular thin films

C.P. Luo

University of Nebraska - Lincoln

David J. Sellmyer

University of Nebraska-Lincoln, dsellmyer@unl.edu

Follow this and additional works at: https://digitalcommons.unl.edu/physicssellmyer

Part of the Physics Commons

Luo, C.P. and Sellmyer, David J., "Structural and magnetic properties of FePt:SiO2 granular thin films" (1999). David Sellmyer Publications. 67.

https://digitalcommons.unl.edu/physicssellmyer/67

This Article is brought to you for free and open access by the Research Papers in Physics and Astronomy at DigitalCommons@University of Nebraska - Lincoln. It has been accepted for inclusion in David Sellmyer Publications by an authorized administrator of DigitalCommons@University of Nebraska - Lincoln. 


\title{
Structural and magnetic properties of $\mathrm{FePt}_{\mathrm{SiO}} \mathrm{S}_{2}$ granular thin films
}

\author{
C. P. Luo a) and D. J. Sellmyer \\ Behlen Laboratory of Physics and Center for Materials Research and Analysis, University of Nebraska, \\ Lincoln, Nebraska 68588-0111
}

(Received 14 June 1999; accepted for publication 16 September 1999)

\begin{abstract}
Nanocomposite $\mathrm{FePt}: \mathrm{SiO}_{2}$ films have been fabricated by annealing the as-deposited $\mathrm{FePt} / \mathrm{SiO}_{2}$ multilayers at temperatures from 450 to $650{ }^{\circ} \mathrm{C}$. These films consist of high-anisotropy tetragonal $L 1_{0} \mathrm{FePt}$ particles embedded in a $\mathrm{SiO}_{2}$ matrix. The structural and magnetic properties of these films were investigated. We have found that coercivity and grain size are highly dependent on the annealing temperature and $\mathrm{SiO}_{2}$ concentration. Films with coercivities in the range from 2 to $8 \mathrm{kOe}$ and grain sizes of $10 \mathrm{~nm}$ or less were obtained. These films have considerable potential as high-density magnetic recording media. (c) 1999 American Institute of Physics.
\end{abstract}

[S0003-6951(99)01446-1]

Equiatomic FePt alloy thin films have attracted significant attention as possible high-density recording media ${ }^{1-4}$ and high energy permanent magnets ${ }^{5}$ because of their exceptional magnetic properties. As well known in the literature, the FePt binary alloy with a tetragonal $L 1_{0}$ structure has a very high-anisotropy constant $K_{1}$ of $7 \times 10^{7} \mathrm{erg} / \mathrm{cc}^{6}$ This high-anisotropy energy is essential for the next generation of recording media with an areal density of $100 \mathrm{Gbit} / \mathrm{in}^{2}$ or higher because such high densities require grain sizes of 10 $\mathrm{nm}$ of less; and with such a small grain size, high-anisotropy energy is needed to retain thermal stability. ${ }^{7,8}$ Furthermore, high-density recording also requires the magnetic particles to be isolated to reduce intergrain interactions, which leads to lower media noise. In this research we investigated the structural and magnetic properties of $\mathrm{FePt}: \mathrm{SiO}_{2}$ granular thin films, which consist of high anisotropy FePt particles embedded in a $\mathrm{SiO}_{2}$ matrix, and their potential for high density media.

$\mathrm{FePt} / \mathrm{SiO}_{2}$ multilayers were deposited on 7059 glass substrates by dc- and rf-magnetron sputtering. The base pressure of the sputtering chamber was $2 \times 10^{-7}$ Torr and high purity Ar was used for deposition at a pressure of 5 mTorr. Compositions were adjusted by changing the FePt- and $\mathrm{SiO}_{2}$-layer thicknesses. The structures of the thin films were studied by x-ray diffraction (XRD) with $\mathrm{Cu} K_{\alpha}$ radiation. Magnetic properties were measured by a superconducting quantum interference device and an alternating gradient field magnetometer.

Multilayers of the composition (FePt- $x \AA / \mathrm{SiO}_{2}$ $-15 \AA)_{n}$ with $x=0,13,17,25,50,75$, and $100 \AA$ were fabricated, with the total FePt layer thickness near $500 \AA$ by adjusting $n$. The as-deposited films contain a disordered $\mathrm{Fe}-\mathrm{Pt}$ face-centered cubic (fcc) structure and are magnetically soft. After annealing in vacuum in a temperature range from 450 to $650{ }^{\circ} \mathrm{C}$, the films undergo a phase transition from the disordered fcc structure to the ordered face-centered tetragonal (fct) structure, which is characterized by the (001) and (002) superlattice peaks of the XRD scans. The longrange order parameter ${ }^{9}$ which quantifies the order-disorder

${ }^{a)}$ Electronic mail: cluo@unlserve.unl.edu transition, is measured by the integrated intensity of the superlattice peaks. As shown in Fig. 1, a highly ordered fct structure with strong (001) and (002) peaks was observed in films with thick FePt layers $(x=50-100 \AA)$ after annealing at $650{ }^{\circ} \mathrm{C}$ for $2 \mathrm{~h}$. As the FePt layer thickness decreases, the long-range order parameter decreases as indicated by the increasing intensity of the (200) peak. A much lower order parameter is implied by the weak superlattice peaks as the FePt-layer thickness decreases to $25 \AA$. Compared with the XRD scan of a pure FePt film as shown in Fig. 1(a), the (111) peaks in Figs. 1(b), 1(c), and 1(d) almost disappear.

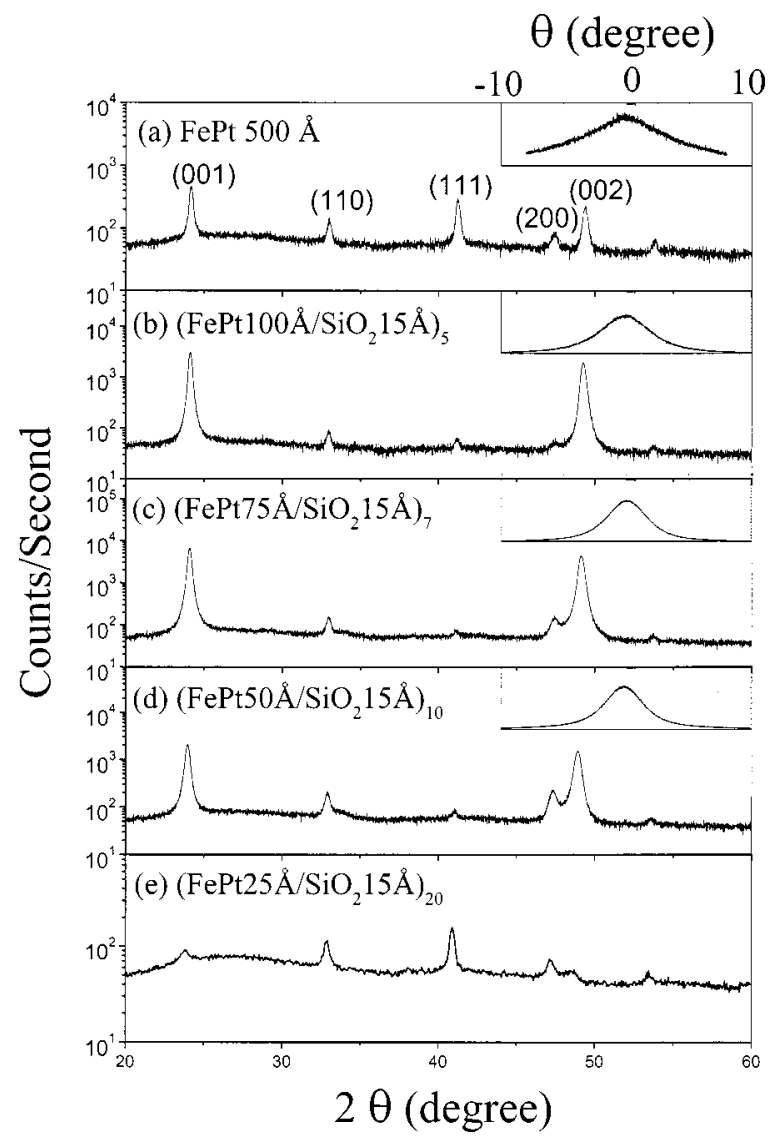

FIG. 1. XRD scans of $\left(\mathrm{FePt} x \AA / \mathrm{SiO}_{2} 15 \AA\right)_{n}$ multilayers annealed at $650{ }^{\circ} \mathrm{C}$ for $2 \mathrm{~h}$. The insets are the (001) peak rocking curves. 


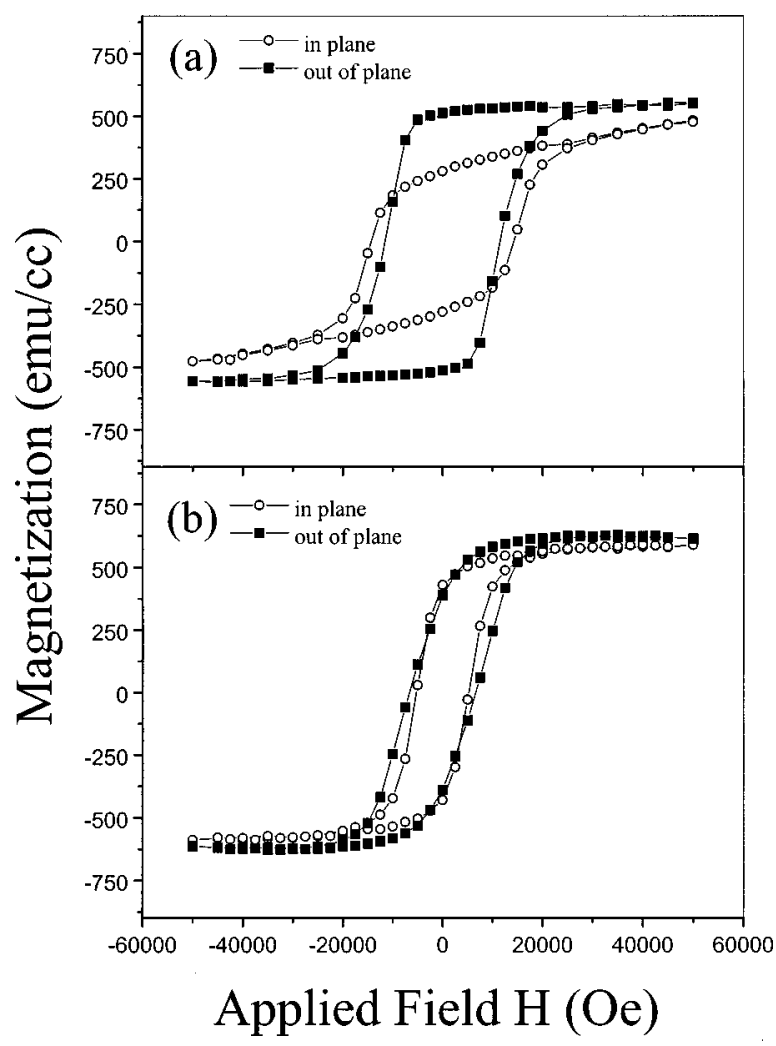

FIG. 2. Hysteresis loop of (FePt100 $\left.\AA / \mathrm{SiO}_{2} 15 \AA\right)_{5}$ annealed at: (a) $650{ }^{\circ} \mathrm{C}$ for $2 \mathrm{~h}$ and (b) $550{ }^{\circ} \mathrm{C}$ for $30 \mathrm{~min}$.

The disappearance of the (111) peaks in these scans and the narrow (001) peak rocking curves indicate that the $c$ axes of the grains are mainly oriented along the film normal direction.

The ordered fct phase is highly anisotropic with $K_{1} \sim 7$ $\times 10^{7} \mathrm{erg} / \mathrm{cc}$. Large coercivities are expected from the ordered films. Figure 2(a) shows the hysteresis loops of the $\left.\left(\begin{array}{lll}\mathrm{FePt} & 100 \AA & \AA\end{array}\right) / \mathrm{SiO}_{2} \quad 15 \AA\right)_{5}$ multilayer annealed at $650{ }^{\circ} \mathrm{C}$ for $2 \mathrm{~h}$. Since the grain $c$ axis is along the film normal direction, perpendicular anisotropy has been observed. A large coercivity of $H_{c} \sim 15 \mathrm{kOe}$ was obtained.

Figure 3 shows the dependence of magnetic moment, coercivity, and grain size on $\mathrm{SiO}_{2}$ concentration. The decrease of $M_{s}$ with increasing $\mathrm{SiO}_{2}$ concentration is due to the dilution of $\mathrm{SiO}_{2}$. Grain sizes were estimated by the Scherrer formula: ${ }^{9} d=0.9 \lambda /\left(B \cos \theta_{B}\right)$. The decrease of grain size with increasing $\mathrm{SiO}_{2}$ concentration implies that $\mathrm{SiO}_{2}$ hinders grain growth. The decrease of $H_{c}$ may be due to the decrease of the order parameter and grain size, which will be analyzed further.

The order parameter, the grain size, and the magnetic properties are highly dependent on the annealing temperature and time. Figure 4 shows the XRD patterns of $\left(\begin{array}{llll}\mathrm{FePt} & 100 \AA / \mathrm{SiO}_{2} & 15 & \AA\end{array}\right)_{5}$ multilayer annealed at $550{ }^{\circ} \mathrm{C}$ for $30 \mathrm{~min}$. Compared with the XRD patterns in Fig. 1(b), the increasing intensity of the (111) peak and the broadening of the rocking curve indicate the degraded (001) texture. Randomly orientated grains cause the disappearance of the perpendicular anisotropy. Magnetic measurements show almost identical in-plane and out-of-plane hysteresis loops, as shown in Fig. 2(b). The broadening of the diffraction peaks implies smaller grain size. The dependence of grain size and Downloaded 17 Nov 2006 to 129.93.16.206. Redistribution subject

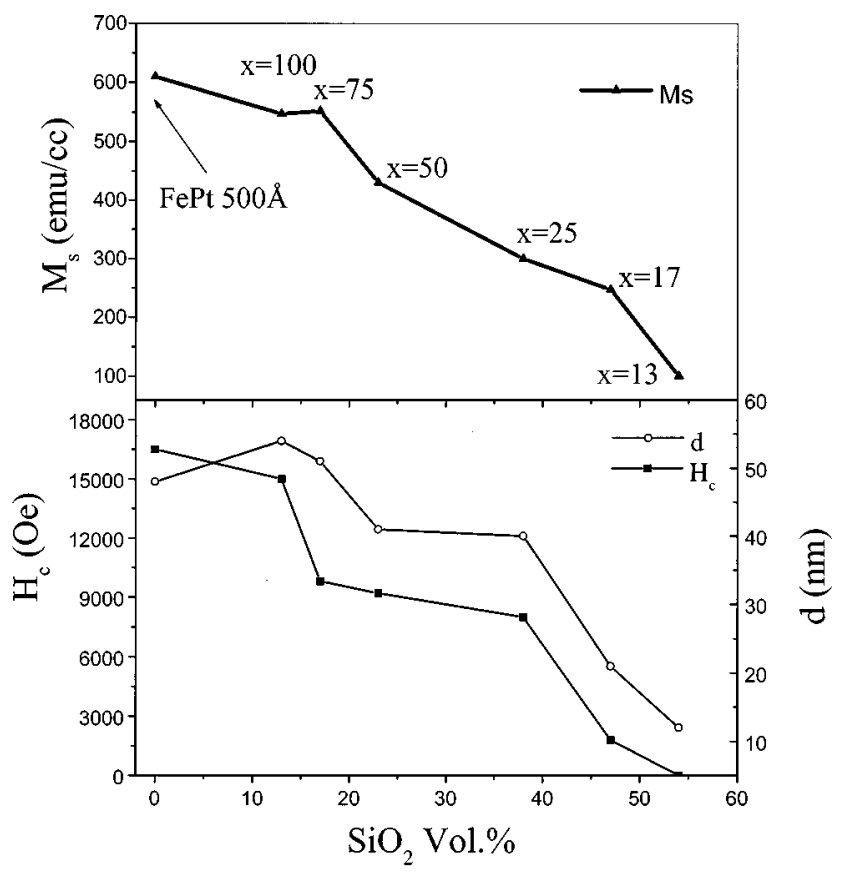

FIG. 3. The dependence of $M_{s}, H_{c}$, and grain size $d$ on $\mathrm{SiO}_{2}$ concentration

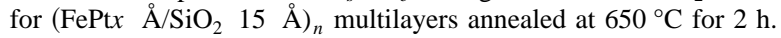

coercivity on the annealing temperature is shown in Fig. 5. For a pure FePt thin film, the grain is large even at relatively low annealing temperature. For example, the grain size is about $27 \mathrm{~nm}$ for the film annealed at $450{ }^{\circ} \mathrm{C}$. The grains grow bigger as annealing temperature increases. Large coercivities were obtained in pure FePt thin film because they are highly ordered even when annealed at relatively low temperatures. For $\mathrm{FePt} / \mathrm{SiO}_{2}$ multilayers, the grains are small $\left(\sim 10 \mathrm{~nm}\right.$ or less) when annealed at $600{ }^{\circ} \mathrm{C}$ or lower temperatures. Grains get much larger as the annealing temperature increases to $650{ }^{\circ} \mathrm{C}$. The coercivities do not decrease as quickly as grain sizes do when decreasing annealing temperature, since the coercivity also depends mostly on the order parameter, while the order parameter depends not only on the annealing temperature but also on the $\mathrm{SiO}_{2}$ concentration. Low $\mathrm{SiO}_{2}$ concentration films can become highly or-

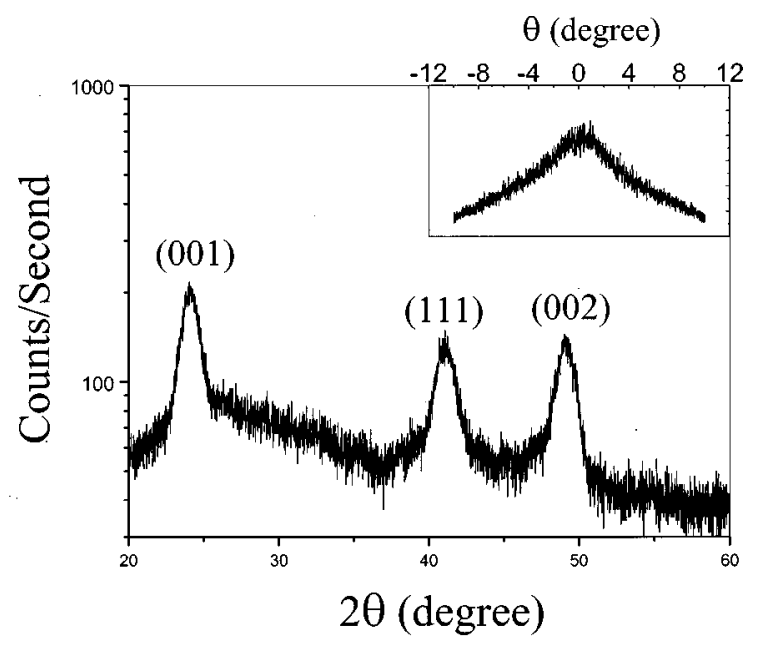

FIG. 4. XRD $\theta-2 \theta$ scan and (001) peak rocking curve for $\left(\text { FePt } 100 \AA / \mathrm{SiO}_{2} 15 \AA\right)_{5}$ annealed at $550{ }^{\circ} \mathrm{C}$ for $30 \mathrm{~min}$. to AIP license or copyright, see http://apl.aip.org/apl/copyright.jsp 


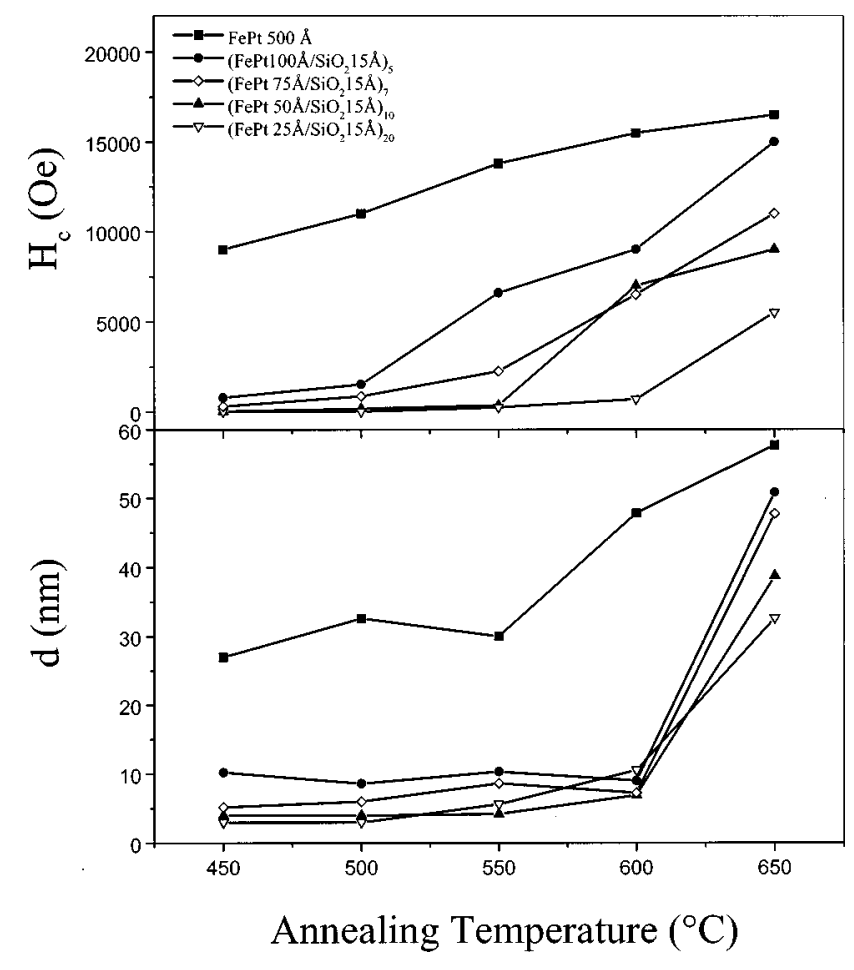

FIG. 5. Dependence of grain size $d$ and coercivity $H_{c}$ on annealing temperatures. The annealing time is $30 \mathrm{~min}$.

dered under relatively low annealing temperatures. Coercivities adjustable between 2 and $8 \mathrm{kOe}$ and small grains $(\sim 10$ $\mathrm{nm}$ or less) were found in films annealed at $600{ }^{\circ} \mathrm{C}$ and lower temperatures. These coercivity values and fine grain size make these films a potential candidate for high density magnetic recording media.

High density recording also requires magnetic grains to be isolated to reduce intergrain interaction, which leads to lower media noise. In Fig. 6, $\delta M$ measurements show strong exchange interactions in the FePt single layer film, while in the $\mathrm{FePt}: \mathrm{SiO}_{2}$ composite films smaller dipole interactions were observed, which support the picture that single-domain FePt particles are isolated by the $\mathrm{SiO}_{2}$ matrix.

In summary, $\mathrm{FePt}: \mathrm{SiO}_{2}$ granular thin films with high anisotropy $\mathrm{FePt}$ particles embedded in a $\mathrm{SiO}_{2}$ matrix were successfully prepared. The grain sizes and coercivities of these

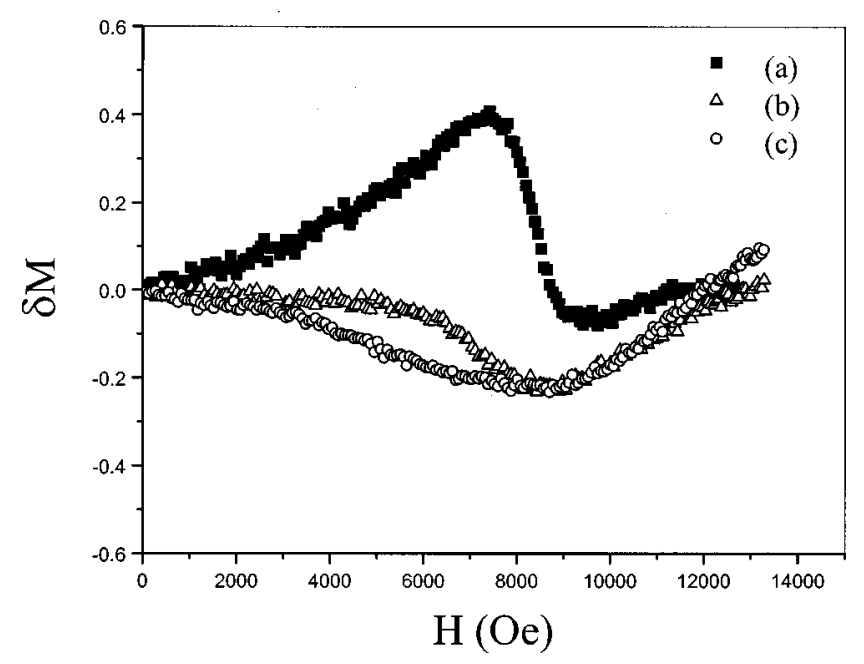

FIG. 6. $\delta M$ plots for: (a) FePt $50 \mathrm{~nm}$ single layer film annealed at $450{ }^{\circ} \mathrm{C}$ for 30 min, (b) $\left(\mathrm{FePt} 50 \AA / \mathrm{SiO}_{2} 15 \AA\right)_{10}$, and (c) $\left(\mathrm{FePt} 75 \AA / \mathrm{SiO}_{2} 15 \AA\right)_{7}$ annealed at $600{ }^{\circ} \mathrm{C}$ for $30 \mathrm{~min}$.

films depend on the annealing temperature and $\mathrm{SiO}_{2}$ concentration. For fixed processing conditions, coercivity and grain size decrease rapidly as $\mathrm{SiO}_{2}$ concentration increases. Under suitable processing conditions, films were obtained with grain size less than $10 \mathrm{~nm}$ and with coercivities in the range of 2-8 kOe. Adjustable coercivity, fine grain size, and reduced intergrain interactions make this composite system a promising candidate for high-density recording media.

This research is supported by Grant No. DOE-DE-FG0398ER45703 and CMRA.

${ }^{1}$ C. P. Luo and D. J. Sellmyer, IEEE Trans. Magn. MAG-31, 2764 (1995).

${ }^{2}$ K. R. Coffey, M. A. Parker, and J. K. Howard, IEEE Trans. Magn. MAG31, 2737 (1995).

${ }^{3}$ C. P. Luo, Z. S. Shan, and D. J. Sellmyer, J. Appl. Phys. 79, 4899 (1996).

${ }^{4}$ N. Li and B. M. Lairson, IEEE Trans. Magn. MAG-35, 1077 (1999).

${ }^{5}$ J. P. Liu, C. P. Luo, Y. Liu, and D. J. Sellmyer, Appl. Phys. Lett. 72, 483 (1998).

${ }^{6}$ B. Zhang and W. A. Soffa, IEEE Trans. Magn. MAG-26, 1388 (1990).

${ }^{7}$ M. Yu, M. F. Doerner, and D. J. Sellmyer, IEEE Trans. Magn. MAG-34, 1534 (1998).

${ }^{8}$ D. N. Lambeth, E. M. T. Velu, G. H. Bellesis, L. L. Lee, and D. E. Laughlin, J. Appl. Phys. 79, 4496 (1996).

${ }^{9}$ B. E. Warren, X-Ray Diffraction (Addison-Wesley, Reading, MA, 1969). 